УДК 659.1

DOI: $10.52575 / 2687-0967-2021-48-4-933-941$

\title{
Социальные сети муниципальных депутатов: проблемы и перспективы (пример г. Ярославля)
}

\author{
Абрамовский И.С., Огурцова Е.В. \\ Ярославский государственный университет им. П.Г. Демидова, \\ Россия, 150003, г. Ярославль, ул. Советская, д. 14 \\ E-mail: abrams25@rambler.ru, katyaogurtsova@yandex.ru
}

\begin{abstract}
Аннотация. Ведение социальных сетей - одно из обязательных требований к успешной деятельности политика в нынешних реалиях, а также важная часть процесса функционирования политической системы. В статье описывается исследование социальных сетей муниципальных депутатов, проведённое в октябре 2020 года. Авторы проанализировали профили 20 депутатов муниципалитета города Ярославля в социальных сетях ВКонтакте, Facebook и Instagram с целью выявления основных стратегий ведения социальных сетей муниципальными депутатами. В результате исследования была получена классификация депутатов по уровню ведения социальных сетей с делением на «депутатов-активистов», «депутатов-формалистов», «красиво живущих депутатов» и «отстающих депутатов». В исследовании применяются контент-анализ и сравнительный метод, а также используется сервис анализа социальных сетей Popsters. Основываясь на полученных данных, авторы приходят к выводу, что муниципальным депутатам следует разнообразить контент и уделить внимание «экспертным» публикациям.
\end{abstract}

Ключевые слова: социальные сети, муниципальные депутаты, общество, коммуникация.

Для цитирования: Абрамовский И.С., Огурцова Е.В. 2021. Социальные сети муниципальных депутатов: проблемы и перспективы (пример г. Ярославля). Via in tempore. История. Политология. 48 (4): 933-941. DOI: 10.52575/2687-0967-2021-48-4-933-941.

\section{Social networks of municipal deputies: problems and prospects (example of Yaroslavl)}

\author{
Ilya S. Abramovsky, Ekaterina V. Ogurtsova \\ Yaroslavl State University, \\ 14 Sovetskaya St., Yaroslavl 150003, Russia \\ E-mail: abrams25@ rambler.ru, katyaogurtsova@yandex.ru
}

\begin{abstract}
Having social media is one of the essential requirements in sufficient politicians' career in nowadays reality as well as a meaningful part of functioning of a political system. The article describes a research about municipal deputies' social media, which was conducted in October 2020. The authors have analyzed profiles of 20 Yaroslavl politicians in such social-network sites as VKontakte, Facebook and Instagram to reveal the main strategies of posting. The results of the study are represented in a classification of the officials due to their activity level in the abovementioned media: «enthusiastic bloggers», «formalists», «having dolce vita» and «falling behind». In the course of the research were used content-analysis and comparative method alongside with the service for social media analysis «Popsters». Based on the obtained data the authors arrived at the conclusion that the municipal deputies should diversify the content and focus on more expert topics.
\end{abstract}

Keywords: social networks, municipal deputies, society, communication

For citation: Abramovskij I.S., Ogurcova E.V. 2021. Social networks of municipal deputies: problems and prospects (example of Yaroslavl). Via in tempore. History and political science. 48 (4): 933-941 (in Russian). DOI: 10.52575/2687-0967-2021-48-4-933-941. 


\section{Введение}

В настоящее время социальные сети - это неотъемлемая часть жизни практически каждого человека. В социальных сетях люди проводят много времени, общаясь между собой, отдыхая. Так, по данным на 2019 год, в социальных сетях россияне проводят в среднем 183 минуты в день. При этом чем моложе аудитория соцсети, тем больше времени она проводит онлайн [Аудитория социальных сетей..., 2021]. С недавнего времени социальные сети стали ещё и инструментом продвижения себя и своих идей в обществе - так появились блогеры, местные лидеры мнений и прочие.

При этом под социальными сетями понимается платформа, онлайн-сервис или вебсайт, предназначенные для построения, отражения и организации социальных взаимоотношений в Интернете. Коммуникации в социальных сетях наравне с личными сообщениями ведутся через посты. Пост - это публикация в социальной сети, которая включает в себя текст, прикрепленное к нему фото-, видео- или аудиоматериал. Под контентом понимается любое информационно значимое наполнение социальной сети (тексты, графика, мультимедиа).

Наиболее популярными социальными сетями в России являются ВКонтакте и Instagram. Социальная сеть Facebook в России не пользуется большой популярностью. Особенность Ярославской области состоит в том, что аудитория Facebook больше, чем в целом по России, и данная социальная сеть пользуется большой популярностью, также как ВКонтакте и Instagram. ВКонтакте и Instagram наиболее популярны у аудитории 16-24 лет, a Facebook - у аудитории старше 45 лет [Аудитория социальных сетей..., 2021].

Ведение социальных сетей стало способом воздействия на общество, электорат. Поэтому, ведение социальных сетей - одно из обязательных требований к успешной деятельности политика в сложившихся условиях. Это также относится и к муниципальным депутатам: и для победы на выборах, и в дальнейшей работе. Социальные сети помогают лучше контактировать с избирателями, выявлять наиболее острые проблемы, а также доносить до граждан свои мысли и идеи. Это делает социальные сети наиболее удобным способом обратной связи, поэтому муниципальным депутатом важно использовать их в своей работе.

Взаимодействие аудитории социальных сетей с авторами, тем более если в этой роли выступают муниципальные депутаты, вписывается в концепцию политической системы, предложенной Дэвидом Истоном. Эта система представляет собой элементы входа информации, которая выражается в импульсах требований и поддержки. Система их обрабатывает и принимает решение - выходы. От них идет обратная связь [Истон, 2015]. Пользователи пишут в социальных сетях сообщения: проблемы, требования (в личных сообщениях депутатам, в комментариях, в постах) или поддержку (через лайки, комментарии, посты-благодарности) политикам. Депутаты видят эти обращения и реагируют на них, принимая решения. Результатом решения они делятся в соцсетях: через посты и ответы на комментарии. Тем самым пользователи получают обратную связь.

Таким образом, в рамках представленной модели ведение депутатом своих социальных сетей открыто и активно - важный фактор функционирования политической системы.

\section{Теоретические основы исследования}

Одним из основоположников исследований интернет-коммуникаций стал Говард Рейнгольд - в 2002 году была опубликована его работа «Умная толпа: новая социальная революция», в которой он рассмотрел влияние цифровых инструментов коммуникации на общество [Рейнгольд, 2002]. Он показал, как массовое распространение телекоммуникационных мобильных технологий влечет за собой не только значимый количественный, но, что более важно, качественный социальный эффект [Абрамов, 2006].

Вопрос о влиянии цифровых технологий на политическую коммуникацию ставят М. Бреслер, Р. Мурзагулов, А. Сулейманов. В работе «Трансформация политической ком- 
муникации и PR-деятельности в цифровом обществе» они рассматривают на основе системного подхода концепцию политической коммуникации, в рамках которой формируется множество политических акторов, взаимодействующих друг с другом [Бреслер, 2019]. Каждый участник коммуникации может быть как актором, генерирующим контент передающим информацию, так и потребителем информации.

Тема ведения социальных сетей политическими акторами также раскрывается в работах множества авторов. Стоит отметить, что современные работы по этой теме очень близки к области маркетинга и SMM. Например, в таком ключе рассматривается продвижение политика в соцсетях. Само понятие определяет как планируемые акции по привлечению общественного внимания к какому-либо изделию, идеи, лицу ${ }^{207}$. Так, в своей работе «Аспекты создания и продвижения персонального бренда современного политика» О. Питько затрагивает тему продвижения личного бренда политика в социальных сетях, что само по себе является маркетинговым мероприятием [Питько, 2016].

И.В. Гаврилов исследовал персональные Интернет-ресурсы депутатов Государственной Думы Федерального Собрания Российской Федерации VI и VII созывов при помощи стандартизированного поискового запроса, включавшего ФИО каждого из парламентариев, а также слова «депутат», «персональный сайт», «Facebook» и «ВКонтакте», выявлял наличие у этих политических акторов персональных веб-ресурсов (учитывалось наличие персонального веб-сайта, официальных аккаунтов в социальных сетях «Facebook» и «ВКонтакте» или микроблоге «Twitter»), индексируемых Яндексом как ключевым поисковым инструментом российского сегмента Интернета [Гаврилов, 2017].

Исследователи также изучают влияние различных инструментов социальных медиа на общественные процессы, а также специфику их применения. С. Шомова в работе «Выборы Президента РФ - 2018 в зеркале мемов: новые реалии политической коммуникативистики», как следует из названия, анализирует специфику применения интернет-мемов в политической кампании 2018 года. При этом автор рассматривает мем, с одной стороны, как спонтанный продукт творчества масс, а с другой - как инструмент политических PRтехнологий [Шомова, 2019]. Шомова выявила, что мемы составляли большую часть политического контента, транслируемых в социальных медиа.

В политической практике эксперты все более обращают внимание на работу губернаторского корпуса в социальных сетях и мессенджерах. Здесь стоит отметить Центр политической конъюнктуры (ЦПК), который формирует так называемые цифровые портреты глав российских регионов ${ }^{208}$ и составляет рейтинги. Так, например, ведение губернаторами страниц в Instagram эксперты ЦПК оценивали по 6 критериям [Сторис успеха..., 2021]: подписчики, лайки, комментарии, вовлеченность, хештеги, функциональность. Также фонд «Петербургская политика» совместно с политконсультантом Леонидом Давыдовым проводят мониторинги деятельности глав регионов в публичном пространстве. Среди них еженедельный рейтинг губернаторов по упоминаемости в телеграм-каналах [Упоминаемость губернаторов..., 2021]. В таком ключе авторы телеграм-канала «Незыгарь» предприняли попытку анализа социальных сетей. В августе 2021 года «Незыгарь» опубликовал доклад «Параметры коммуникации губернаторского корпуса с обществом (итоги первого полугодия 2021 г.)», в котором рассмотрели тему ведения социальных сетей главами регионов.

Таким образом, исследовательская база представлена различными видами исследований: теоретических и прикладных, в междисциплинарной сфере. Такой подход позволяет рассмотреть тему с различных сторон.

207 Продвижение в социальных сетях - цели и стратегии SMM. 2019-2020 URL: https://medialike.ru/prodvizhenie-v-soczialnyh-setyah/

${ }^{208}$ Цифровые портреты глав российских регионов (cpkr.ru). 2020-2021 URL: https://cpkr.ru/issledovaniya/tsifrovye-portrety-glav-rossiyskikh-regionov/ 


\section{Социальные сети муниципальных депутатов в Ярославле}

Сегодня существует множество различных по аудитории, формату и охвату пользователей социальных сетей, из которых каждая имеет свою специфику. Специфика ситуации заключается в том, что многие муниципальные депутаты ведут свои социальные сети несистемно, неактивно и не используют социальные сети как инструмент коммуникации с населением.

В октябре 2020 года мы проводили исследование форматов работы в социальных сетях политиков. В качестве объекта исследования выступили социальные сети муниципальных депутатов. Предметом - стратегии ведения страниц в социальных сетях муниципальными депутатами. Целью исследования было выявление основных стратегий ведения социальных сетей муниципальными депутатами.

Под стратегией ведения социальной сети мы понимаем целенаправленную работу в социальной сети, подразумевающую определенную частоту постинга, тематику постов, открытость к комментариям аудитории. То есть это некий стиль ведения страницы в социальной сети, позиционирование в социальных сетях.

В рамках исследования было сформулировано три базовых гипотезы:

- депутаты муниципалитета редко используют социальные сети как инструмент коммуникации с электоратом;

- депутаты муниципалитета редко публикуют контент в социальных сетях;

- $\quad$ контент, публикуемый депутатами, чаще не отражает их деятельность как депутатов, не характеризует их как экспертов в своей области.

В состав муниципалитета г. Ярославля входят 38 депутатов. В структуре муниципалитета находятся 4 фракции: ЕР, КПРФ, ЛДПР, СР. Выборка составила 20 депутатов. Выборка случайная, из общего списка депутатов, который представлен на сайте муниципалитета [Состав и структура..., 2020], в выборку включался каждый второй депутат. То есть в выборку попали второй депутат в списке, четвертый, шестой, восьмой и так далее. В результате в выборку вошли депутаты всех 4 фракций. Таким образом, выборка репрезентативная, поскольку повторяет фракционное представительство муниципалитета.

В исследовании использовались сервисы анализа социальных сетей, контентанализ, сравнительный метод. Мы проанализировали страницы депутатов муниципалитета города Ярославля в социальных сетях Facebook, Instagram, ВКонтакте. Были выбраны следующие критерии анализа. Присутствие в социальных сетях, показатели: наличие страницы в Facebook, страницы во ВКонтакте, наличие профиля в Instagram. Частота постинга, показатель: число публикаций в месяц (часто - 15-20, средне - 10-15, редко до 10, нет публикаций). Тематика постов, показатель: число постов по определенной тематике в месяц (тематики - рассказ о работе, рассказ о личной жизни, экспертные комментарии). Активность аудитории, показатель: индекс активности, который считается путем сложения среднего числа лайков за месяц и среднего числа комментариев за месяц с коэффициентом 4. Работа с аудиторией, показатель: шкала открытости к аудитории (1. комментарии закрыты; 2. комментарии открыты, но аудитория не реагирует; 3. комментарии открыты, аудитория реагирует, депутат не отвечает; 4. комментарии открыты, аудитория реагирует, депутат отвечает). Заполненность страницы, показатели: информация о себе $(+1)$, информация о месте работы $(+1)$, наличие ссылки на страницы в других соцсетях (+1 за каждую ссылку), информация об увлечениях и интересах.

Исследование проводилось с помощью онлайн-сервиса Popsters [Popsters - статистика..., 2020], который позволяет анализировать посты и страницы в соцсетях, сравнивает и определяет эффективность публикаций.

Публикации депутатов в каждой социальной сети были распределены по содержанию на группы: «рабочие» публикации, личные интересы и хобби, экспертные комментарии. Чтобы отнести пост к одной из групп, мы определяли его содержание. Если в публи- 
кации содержится информация о работе депутата (фотографии с заседаний, работы в округе, текстовая информация о достигнутых результатов) либо по основному месту работы, публикация относится к «рабочей». Если в публикации говорится о досуге, интереcax, увлечениях и хобби, фотографии с поездок, информация о каких-либо личных достижениях, публикация относится к «личным». Если в публикации содержится комментарий событий в городе, области или стране, относящийся к сфере компетенций автора, если дано разъяснение по каким-либо вопросам с точки зрения депутата, публикация относится к «экспертным».

\section{Итоги}

В ходе исследования мы выявили, что, во-первых, не все депутаты имеют страницы в ВКонтакте, Facebook или Instagram; во-вторых, все депутаты дублируют контент, выкладывая одни и те же публикации в разных социальных сетях; в-третьих, между депутатами существует разброс в частоте постинга и тематике контента.

В результате анализа страниц депутатов мы сформировали следующую классификацию: «депутаты-активисты», «депутаты-формалисты», «красиво живущие депутаты» и «отстающие депутаты».

«Депутаты-активисты» - это те депутаты, которые активно ведут свои социальные сети. Такие депутаты имеют аккаунты в двух или трех социальных сетях, не скрывают свой род деятельности, в постах рассказывают о работе [В округе завершается..., 2020]. Информация «о себе» в профиле указывает на депутатство. «Депутаты-активисты» часто публикуют записи на своих страницах в социальных сетях, и на эти записи реагирует аудитория депутатов. Также сами депутаты общаются со своей аудиторией: отвечают на комментарии, проводят прямые эфиры.

«Депутаты-формалисты» присутствуют в социальных сетях, но формально: большая часть из них пустует. Депутат просто зарегистрирован в социальной сети, но практически не занимается ведением своей страницы. У некоторых страницы наполнены поздравлениями, записями других пользователей. Есть те, у кого из активности на странице только партийная агитация, опубликованная в период перед выборами. Такие страницы могут «активизироваться» [При беспрецедентном..., 2020] во время предвыборной кампании и после ее завершения «затухают». Ещё один вариант: страница наполнена постами, написанными сухо и неинтересно, для галочки [Ярославлю присвоено.., 2020]. Все приведенные варианты объединяет одна черта: активность на странице низкая и стимулируется извне. Таким страницам характерно отсутствие отклика от аудитории, низкая степень её вовлеченности.

«Красиво живущие депутаты» выкладывают в основном красивые фотографии своей жизни: пейзажи, путешествия, семья, охота-рыбалка, книги или любой другой досуг [И вот я снова..., 2020]. На таких страницах отсутствует экспертный и профессиональный контент. Такие депутаты могут присутствовать как во всех социальных сетях, так и только в одной. Информация в профиле может указывать на депутатскую деятельность, но публикации говорят об обратном. Активность пользователей может быть, но, как правило, это друзья, родственники или знакомые.

«Отстающие депутаты» либо не имеют страниц в социальных сетях, либо присутствуют максимум в одной и не ведут свою страницу там. Возможно, есть закрытые страницы только для «своих».

К «депутатам-активистам» мы отнесли: председателя Муниципалитета Артура Ефремова, депутатов Дмитрия Петровского и Наталию Бобрякову. К «депутатамформалистам» отнесены: депутаты Марина Дьячевская, Сергей Зубов, Анатолий Каширин, Олег Ненилин. «Красиво живущие депутаты»: Дмитрий Волончунас, Илья Горохов, Юлия Миронова, Дмитрий Соколов. «Отстающие депутаты»: Андрей Ганелин, Павел Зи- 
боров, Вадим Канашкин, Андрей Лихачев, Алексей Морозов, Алексей Таганов, Александр Черепанин, Михаил Шабанов.

Таким образом, мы сформулировали рекомендации для депутатов г. Ярославля:

1. Стараться использовать возможности площадок по-максимуму.

Так, в Instagram есть возможность проводить прямые эфиры, выкладывать так называемые «истории», создавать подборки «историй» - «актуальное», выкладывать видео IGTV и пр. Хороший пример ведения Instagram - Дмитрий Юнусов, глава Тутаевского муниципального района. Во ВКонтакте аналогичные возможности: прямые эфиры, истории.

2. Поддерживать не только образ депутата или не только образ любителя природы. Развивать в социальных сетях свои разные стороны.

3. Добавить экспертных постов.

4. Добавить узнаваемые рубрики, хэштеги.

5. Вовлекать аудиторию при помощи соответствующих механик.

Для «депутатов-активистов» главная рекомендация - более узнаваемый контент. Так, например, у А.Е. Ефремова есть прямые эфиры, и проект «Люди Дела» [Сегодня в проекте, 2020] - это «фишки» его профиля. То, что ассоциируется с его социальными сетями, запоминается. Таких узнаваемых рубрик не хватает депутатам. Также контент можно сделать чуть более разнообразным, ориентированным на целевые аудитории социальных сетей, либо же исключительно на электорат депутата.

«Депутатам-формалистам» мы рекомендуем начать стабильно вести больше чем одну социальную сеть. Важно публиковать разнообразный контент, не только поздравления и агитация. Что постить, можно посмотреть у коллег из списка выше: отчеты о выездах, о проделанной работе, рассказы о своих увлечениях и хобби, свою точку зрения на те или иные проблемы и т. д. Выход на новые площадки увеличит охват аудитории, а более открытый и стабильный постинг повысит лояльность аудитории.

Рекомендация для «красиво живущих депутатов» - добавить в свои социальные сети посты о депутатской деятельности, возможно, о работе. Также по возможности комментировать какие-то ситуации, показывать свою экспертность в той или иной области.

Для «отстающих» - у кого закрытый профиль - создать приватный аккаунт для близких друзей и сделать его закрытым и отдельный открытый рабочий аккаунт, где освещать свою деятельность и поддерживать образ не только депутата, но и эксперта в той или иной области. Для тех, у кого вообще нет никаких социальных сетей, либо все закрыты - начать вести открыто хотя бы одну, коммуницировать с аудиторией.

Таким образом, в ходе исследования мы выявили, что депутаты Муниципалитета мало внимания уделяют социальным сетям. Страницы в социальных сетях ведутся посредственно: недостаточно заполнен профиль, однообразный контент в публикациях, отсутствует работа с аудиторией. В большинстве случаев есть два варианта ведения социальной сети: либо много постов про депутатскую деятельность, либо в основном посты «про жизнь» (поездки, хобби, увлечения, фотографии красивых мест и природы).

У депутатов существует «основная соцсеть» - социальная сеть, в которой они публикуют весь контент, часть которого затем дублируется в остальные соцсети. В большинстве случаев это Facebook. Объясняется это тем, что в Ярославской области Facebook самая популярная соцсеть, в особенности в деловой сфере. В «основной соцсети» более высокие показатели активности аудитории.

Стоит выделить особенность Facebook. В социальной сети есть возможность отмечать других пользователей, в результате публикация показывается на странице отмеченного пользователя. Таким образом, даже не публикуя собственный контент, но активно принимая участия в крупных событиях, депутат может «формировать» свой профиль.

13 сентября в Ярославской области проходили дополнительные выборы депутата Государственной Думы по одномандатному избирательному округу № 194. В период пе- 
ред днем голосования и несколько дней после на страницах некоторых депутатов была большая активность. Основным контентом в этот период была предвыборная агитация. Также в этот период было много постов поддержки кандидатов. В частности, посты \#ЗаКоваленко и \#ЗаЛисицына. Соответственно, после завершения кампании активность депутатов упала.

Депутаты пишут либо «рабочие» посты, либо посты «про жизнь», при этом постов с экспертными комментариями нет. Единственный депутат, который регулярно публикует комментарии по актуальным событиям в области и стране - Дмитрий Петровский.

Таким образом, гипотеза подтвердилась. Депутатам муниципалитета г. Ярославля стоит изменить стратегию ведения социальных сетей, разнообразить контент, уделить внимание «экспертным» публикациям. В такой ситуации граждане получат качественную обратную связь от депутатов, депутаты смогут быстрее получать от жителей запросы на существующие проблемы, решение которых позволит им получать дополнительную поддержку жителей.

Благодарности: авторы выражают глубокую благодарность научному руководителю Соколову Александру Владимировичу, доктору политических наук, заведующему кафедрой социально-политических теорий за помощь в подготовке работы.

\section{Список литературы}

1. Абрамов Р.Н. 2006. Мобильные коммуникационные технологии и повседневность Рейнгольд Г. Умная толпа: новая социальная революция. Журнал социологии и социальной антропологии. 9 (4): 185-192.

2. Аналитический доклад «НЕЗЫГАРЯ» «Параметры коммуникации губернаторского корпуса с обществом» - это отчасти буревестник для губернаторов, которые так и не научились «ходить в народ». 2021. URL - http://rureporter.com/news/62216.

3. Аудитория социальных сетей в России. 2019. 2020. URL: https://popsters.ru/blog/post/auditoriya-socsetey-v-

rossii\#: :text=Средний\%20пользователь\%20проводит\%20в\%20интернете,года\%3А\%20194\%20мин уты\%20в\%20день.

4. Бреслер М.Г., Мурзагулов Р.Р., Сулейманов А.Р. 2019. Трансформация политической коммуникации и PR-деятельности в цифровом обществе. Журнал политических исследований. $3(3): 125-132$.

5. В округе завершается ремонт дворов по программе «Решаем вместе». 2020. URL: https://vk.com/wall522597973_387

6. Гаврилов И.В. 2017. Исследование персональных интернет-ресурсов депутатов Государственной Думы Федерального Собрания Российской Федерации VI и VII созывов. Политическая экспертиза: ПОЛИТЭКС. 13 (1): 70-81.

7. И вот я снова могу сказать: я в хорошей форме! 2020. URL: https://www.instagram.com/p/CFATfa8Jfug/?utm_source=ig_web_copy_

8. Истон Д. 2015. Подход к анализу политических систем. Вестник Московского университета. Политические науки. 12 (5): 17-37.

9. Питько О.А. 2016. Аспекты создания и продвижения персонального бренда современного политика. Международный журнал прикладных и фундаментальных исследований. 11-6: 1163-1165.

10. При беспрецедентном использовании адмресурса. 2020. URL: https://vk.com/wall44807596_1261.

11. Рейнгольд Г. 2006. Умная толпа: новая социальная революция - Пер. с англ. А. Гарькавого. М, ФАИР ПРЕСС, 416 с.

12. Сегодня в проекте «Люди Дела». 2020 URL: https://www.instagram.com/p/CFzNPKLJTIN/?utm_source=ig_web_copy_

13. Состав и структура муниципалитета. 2017-2021. URL: https://cityyaroslavl.ru/munitsipalitet/sostav-i-struktura-munitsipaliteta/ 
14. Сторис успеха: рейтинг глав регионов в Instagram (cpkr.ru). 2021. URL: https://cpkr.ru/issledovaniya/tsifrovye-portrety-glav-rossiyskikh-regionov/storis-uspekha-reyting-glavregionov-v-instagram/

15. Упоминаемость губернаторов в телеграм-каналах 28 июля - 3 августа 2021 года. 2021. URL: https://davydov.in/politics/upominaemost-gubernatorov-v-telegram-kanalax-28-iyulya-3-avgusta2021-goda/

16. Шомова, С.А. 2019. Выборы президента РФ - 2018 в зеркале мемов: новые реалии политической коммуникативистики. Полис. Политические исследования. 3: 157-173. DOI 10.17976/jpps/2019.03.10.

17. Ярославлю присвоено почётное звание «Город трудовой доблести». 2020. URL: https://www.facebook.com/oleg.nenilin.5/posts/3207856795968286

18. Popsters - статистика и аналитика социальных сетей. 2013-2021. URL: https://popsters.ru/app/dashboard.

\section{References}

1. Abramov R.N. 2006. Mobil'nye kommunikacionnye tekhnologii i povsednevnost' Rheingold H. Umnaya tolpa: novaya social'naya revolyuciya [Mobile communication technologies and everyday life. Rheingold H. Smart Mobs: The Next Social Revolution]. ZHurnal sociologii i social'noj antropologii. 9 (4): 185-192.

2. Analiticheskij doklad «NEZYGARYA» «Parametry kommunikacii gubernatorskogo korpusa s obshchestvom» - eto otchasti burevestnik dlya gubernatorov, kotorye tak i ne nauchilis' «hodit' v narod» [The analytical report of «NEZYGAR» "Parameters of communication of the governor's corps with society" is partly a petrel for governors who have not learned to "go to the people»]. 2021. URL http://rureporter.com/news/62216

3. Auditoriya social'nyh setej v Rossii 2019. [The audience of social networks in Russia 2019]. 2020. URL: https://popsters.ru/blog/post/auditoriya-socsetey-vrossii\#: :text=Средний\%20пользователь\%20проводит\%20в\%20интернете,года\%3А\%20194\%20мин уты\%20в\%20день.

4. Bresler M.G., Murzagulov R.R., Sulejmanov A.R. 2019. Transformaciya politicheskoj kommunikacii i PR-deyatel'nosti v cifrovom obshchestve [Transformation of political communication and PR activities in a digital society]. Zhurnal politicheskih issledovanij. 3 (3): 125-132.

5. V okruge zavershaetsya remont dvorov po programme «Reshaem vmeste» [In the district, the repair of courtyards under the «We decide together» program is being completed]. 2020. URL: https://vk.com/wall522597973_387.

6. Gavrilov I.V. 2017. Issledovanie personal'nyh internet-resursov deputatov Gosudarstvennoj Dumy Federal'nogo Sobraniya Rossijskoj Federacii VI i VII sozyvov [Research of personal Internet resources of deputies of the State Duma of the Federal Assembly of the Russian Federation of the VI and VII convocations]. Politicheskaya ekspertiza: POLITEKS. 13 (1): 70-81.

7. I vot ya snova mogu skazat': ya v horoshej forme! [And here I can say again: I'm in good shape!]. 2020. URL: https://www.instagram.com/p/CFATfa8Jfug/?utm_source=ig_web_copy_

8. Iston D. 2015. Podhod k analizu politicheskih sistem. Vestnik Moskovskogo universiteta [An approach to the analysis of political systems]. Politicheskie nauki. 12 (5): 17-37.

9. Pit'ko O.A. 2016. Aspekty sozdaniya i prodvizheniya personal'nogo brenda sovremennogo politika [Aspects of creating and promoting a personal brand of a modern politician]. Mezhdunarodnyj zhurnal prikladnyh i fundamental'nyh issledovanij. 11-6: 1163-1165.

10. Pri besprecedentnom ispol'zovanii admresursa. [With unprecedented use of the admin resource]. 2020. URL: https://vk.com/wall44807596_1261

11. Rheingold H. 2006. Umnaya tolpa: novaya social'naya revolyuciya - Per. s angl. A. Gar'kavogo [Smart Mobs: The Next Social Revolution]. M, FAIR PRESS, $416 \mathrm{s.}$

12. Segodnya v proekte «Lyudi Dela». [Today in the project "People of Business"]. 2020 URL: https://www.instagram.com/p/CFzNPKLJTIN/?utm_source=ig_web_copy_

13. Sostav i struktura municipaliteta. [Composition and structure of the municipality]. 20172021. URL: https://city-yaroslavl.ru/munitsipalitet/sostav-i-struktura-munitsipaliteta/ 
14. Storis uspekha: rejting glav regionov v Instagram (cpkr.ru) [Success story: rating of heads of regions on Instagram (cpkr.ru)]. 2021. URL: https://cpkr.ru/issledovaniya/tsifrovye-portrety-glavrossiyskikh-regionov/storis-uspekha-reyting-glav-regionov-v-instagram/

15. Upominaemost' gubernatorov v telegram-kanalah 28 iyulya -3 avgusta 2021 goda [Mention of governors in telegram channels July 28 - August 3, 2021]. 2021. URL: https://davydov.in/politics/upominaemost-gubernatorov-v-telegram-kanalax-28-iyulya-3-avgusta-2021goda/

16. Shomova S.A. 2019. Vybory prezidenta RF - 2018 v zerkale memov: novye realii politicheskoj kommunikativistiki. Polis. Politicheskie issledovaniya [Russian Presidential Elections 2018 in the Mirror of memes: new realities of Political Communication Studies]. 3: 157-173. DOI 10.17976/jpps/2019.03.10.

17. Yaroslavlyu prisvoeno pochyotnoe zvanie "Gorod trudovoj doblesti" [Yaroslavl was awarded the honorary title "City of Labor Valor"]. 2020. URL: https://www.facebook.com/oleg.nenilin.5/posts/3207856795968286

18. Popsters - statistika i analitika social'nyh setej. [Popsters - statistics and analytics of social networks]. 2013-2021. URL: https://popsters.ru/app/dashboard

Конфликт интересов: о потенциальном конфликте интересов не сообщалось.

Conflict of interest: no potential conflict of interest related to this article was reported.

\section{ИНФОРМАЦИЯ ОБ АВТОРАХ}

Абрамовский Илья Сергеевич, студент кафедры социально политических теорий Ярославского государственного университета, г. Ярославль, Россия

Огурцова Екатерина Валерьевна, студентка кафедры социально политических теорий Ярославского государственного университета, г. Ярославль, Россия

\section{INFORMATION ABOUT THE AUTHORS}

Ilya S. Abramovsky, student of the Department of Socio-Political Theories of Yaroslavl State University, Yaroslavl, Russia

Ekaterina V. Ogurtsova, student of the Department of Socio-Political Theories of Yaroslavl State University, Yaroslavl, Russia 